\begin{tabular}{|c|c|c|}
\hline \hline & Mansoura University & Faculty of Engineering \\
Mansoura Engineering Journal & a
\end{tabular}

\title{
Integrating Dynamic Line Rating in Security Constrained Optimal Power Flow Considering Wind Power Generation
}

\author{
Ahmed A. Elsherpiny, Sobhy M. Abdelkader and Abdelfattah A. Eladl
}

KEYWORDS:
Security-Constrained
Optimal Power Flow
(SCOPF), Dynamic Line
Rating (DLR), Conductor
Temperature
Calculation (CTC),
Particle Swarm
Optimization (PSO),
Probability Density
Function (PDF).

\begin{abstract}
Traditional optimal power flow (OPF) problem is solved considering static line rating (SLR) of the transmission lines which are constant values of power flow limits. This led to underutilization of the network and higher locational marginal prices (LMPs). Dynamic line rating (DLR) is one of the active solutions to enhance ampacity for overhead transmission lines (OHTL), especially with the penetration of high wind power without investing in an additional transmission line network. This paper investigates the effect of integrating the DLR on power dispatch with uncertainty levels due to renewable energy sources (RES) generation. The model propose is a multi-period securityconstrained OPF based on particle swarm optimization (SCOPF/PSO) that takes into consideration the steady-state heat-balance equation (SS-HBE) of the OHTL and the ramp-up time of generation units. The problem is a multiobjective optimization one; the main objective is to maximize the social welfare (SW) by minimizing total system operation cost and maximizing the revenue from the energy consumers, whereas the second objective is to minimize the thermal emissions. To demonstrate the effectiveness of the proposed model, a case study is applied to the modified IEEE 30-bus test system. The results expound on the effectiveness of the proposed approach.
\end{abstract}

\section{NOMENCLATURE}

All the basic symbols used in this paper are mentioned below, in addition to other symbols are defined as required.

Sets of indices

$\mathrm{N}_{\mathrm{g}} \quad$ Number of thermal generator buses

$\mathrm{N}_{\mathrm{w}} \quad$ The number of wind buses

$\mathrm{N}_{\mathrm{TL}} \quad$ Number of Transmission lines

$\mathrm{N}_{\mathrm{b}} \quad$ Number of load (demand)buses
A. Parameters, constants and variables

$\begin{array}{ll}\mathrm{H}_{\mathrm{m}} & \text { The magnetic heating } \\ \mathrm{H}_{\mathrm{j}} & \text { The conducting Joule heating } \\ \mathrm{H}_{\mathrm{r}} & \text { The radiative cooling } \\ \mathrm{H}_{\mathrm{s}} & \text { The solar heating } \\ \mathrm{H}_{\mathrm{c}} & \text { The convective cooling } \\ \mathrm{H}_{\mathrm{e}} & \text { The evaporate cooling } \\ \mathrm{H}_{\mathrm{i}} & \text { The corona heating } \\ \left.\mathrm{R}_{(} \mathrm{T}_{\mathrm{c}}\right) & \text { The conductor resistance depending on } \\ \mathrm{I}_{\mathrm{max}} & \text { Maximum Conductor Ampacity (Rating) } \\ \mathrm{V}_{\mathrm{G}} & \text { The voltage magnitude for generator buses }\end{array}$

Sobhy M. Abdelkader, Electrical Power Engineering Dept., Egypt-Japan University of Science and Technology (E-JUST), New Borg El-Arab, Egypt and Faculty of Engineering, Mansoura University, Mansoura, 35516, Egypt

Abdelfattah A. Eladl, Electrical Engineering Dept., Faculty of Engineering, Mansoura University, Mansoura, 35516, Egypt) 


\begin{tabular}{|c|c|}
\hline$V_{\mathrm{b}}$ & The voltage value of the load bus \\
\hline $\mathrm{V}_{\mathrm{i}} \& \mathrm{~V}_{\mathrm{j}}$ & The voltage value of the $\mathrm{i}^{\text {th }}$ and $\mathrm{j}^{\text {th }}$ bus \\
\hline $\mathrm{P}_{\mathrm{G}}$ & $\begin{array}{l}\text { The power output of the generators except } \\
\text { swing generator }\end{array}$ \\
\hline $\mathrm{P}_{\mathrm{G} 1}$ & The Active output power of the slack generator \\
\hline$Q_{G}$ & Reactive power output of the generator \\
\hline$v_{\text {in }}$ & The cut-in wind speed of the turbine \\
\hline$v_{\mathrm{r}}$ & Rated wind speed of the turbine \\
\hline$v_{\text {out }}$ & Cut-out wind speeds of the turbine \\
\hline $\mathrm{P}_{\mathrm{wr}}$ & The rated output power of the wind turbine \\
\hline $\mathrm{P}_{\mathrm{w}}$ & The output of wind generator \\
\hline$d_{i}$ & The direct cost coefficient for $\mathrm{i}^{\text {th }}$ wind farm \\
\hline $\mathrm{c}$ & Weibull PDF scale parameter \\
\hline $\mathrm{k}$ & Weibull PDF shape parameter \\
\hline $\mathrm{P}_{\mathrm{ws}, \mathrm{i}}$ & The scheduled power for a $\mathrm{i}^{\text {th }}$ wind farm \\
\hline $\mathrm{P}_{\text {wav,i }}$ & The available (actual) power for $\mathrm{i}^{\text {th }}$ wind farm \\
\hline$f_{w}\left(P_{w, i}\right)$ & The wind power PDF for $\mathrm{i}^{\text {th }}$ wind farm \\
\hline $\mathrm{K}_{\mathrm{pw}, \mathrm{i}}$ & $\begin{array}{l}\text { The penalty cost coefficient for over generation of } i^{\text {th }} \\
\text { wind farm }\end{array}$ \\
\hline $\mathrm{K}_{\mathrm{Rw}, \mathrm{i}}$ & $\begin{array}{l}\text { The reserve cost coefficient for under generation of } i^{\text {th }} \\
\text { wind farm }\end{array}$ \\
\hline$a_{i}, b_{i}, c_{i}$ & The cost coefficients of the $\mathrm{i}^{\text {th }}$ thermal generator \\
\hline$\lambda_{\mathrm{i}}$ & The LMPs of bus i (\$/MW) received from the OPF \\
\hline $\begin{array}{l}\omega_{i}, \alpha_{i}, \\
\beta_{i}, \gamma_{i}, \mu_{i}\end{array}$ & The emission coefficients of the thermal generator \\
\hline $\mathrm{P}_{\mathrm{Gi}}, \mathrm{Q}_{\mathrm{Gi}}$ & Aactive and reactive power of the $\mathrm{i}^{\text {th }}$ thermal generator \\
\hline $\mathrm{P}_{\mathrm{Gi}}^{\min }$ & Minimum installed capacity of the $\mathrm{i}^{\text {th }}$ thermal generator \\
\hline $\mathrm{P}_{\mathrm{Gi}}^{\max }$ & Maximum installed capacity of the $\mathrm{i}^{\text {th }}$ thermal generator \\
\hline$P_{D i}, Q_{D i}$ & The active and reactive power of the $\mathrm{i}^{\text {th }}$ bus \\
\hline $\mathrm{S}_{\mathrm{Li}}$ & The apparent power flow in transmission line $\mathrm{i}$ \\
\hline$S_{\mathrm{Li}}^{\max }$ & The maximum apparent power can be flow in line $\mathrm{i}$ \\
\hline$\delta_{\mathrm{ij}}$ & The variance in voltage angles between $i$ and $j$ buses \\
\hline$g_{i j}$ & The conductance between $\mathrm{i}^{\text {th }}$ and $\mathrm{j}^{\text {th }}$ buses \\
\hline$b_{i j}$ & The susceptance between $\mathrm{i}^{\text {th }}$ and $\mathrm{j}^{\text {th }}$ buses \\
\hline $\mathrm{Ta}_{\mathrm{i}, \mathrm{j}}$ & The ambient temperature for line between bus I and $j$ \\
\hline $\mathrm{Tc}_{\mathrm{i}, \mathrm{j}}$ & $\begin{array}{l}\text { The limited conductor temperature of for line between } \\
\text { bus } i \text { and } j\end{array}$ \\
\hline $\mathrm{Tc}_{\mathrm{i}, \mathrm{j}}^{\max }$ & $\begin{array}{l}\text { The maximum conductor temperature for line } \\
\text { between bus } i \text { and } j\end{array}$ \\
\hline
\end{tabular}

\section{NTRODUCTION}

$\mathrm{R}$ ECENTLY, governments have become increasingly aware of the importance of increasing the RES activation to foster national development. Consequently, the increase of RES offers significant economic and harmless benefits to the environment [1]. One of the main operational challenges is the extreme uncertainty of its production strength. Prediction of the available capacity of the RES used in building the generation schedules is generally described with higher levels of uncertainty than the standard in a traditional generation and load prediction [2]. The growing uncertainty in production that can be obtained requires that relatively high-speed spinning reserves be exploited and replaced with real-time production curtailments, which causes the RES energy available in an electrical network to be overestimated [3].

Traditionally, line rating is estimated assuming the worst conditions (low wind speed and high ambient temperature)[4]. The resulting rating marked as SLR can be very conservative and may limit the use of specific transmission paths under the actual available capacity. This affects the scheduled RES generation, which represents the cost of fuel by almost zero. The surrounding climatic conditions around OHTL have a clear effect on the cooling of the conductor as well as on its thermal limits[5-6]. Consequently, the preservative permitted by the SLR approach can be mitigated by validating climatic conditions around the conductor and by using this information to estimate conductivity temperature and portability, this is known as DLR[7-11]. DLR (appears as a real-time thermal rating or as a dynamic line rating) is an innovation that can dynamically enhance OHTL current carrying capacity. It depends on the realization that the conductor's ability is determined by its ability to dissipate the resulting heat. The capacity of the conductor is characterized by the maximum current that meets safety and design in addition to the security standards for overhead conductors[12]. DLR depends on environmental conditions such as solar radiation, ambient temperature, wind speed, and wind direction. At present, to calculate amapcity, only annual conservative assessments of meteorological values are used. In DLR, capacity is a unique variable that gives a moderate calculation of the critical value with which a conductor can operate in every unit of time of the process. The aforementioned phenomenon is especially visible on OHTL, as it can give a great uprising to the line. In the current energy system scenario, where the RES power increase causes the infrastructure to be under pressure, and thus network enhancements become necessary, the DLR provides a solution to accommodate increased renewable energy production while reducing or delaying the network reinforcements. Moreover, like RES production forecasts, improving reliable DLR forecasts is a necessary solution for integrating DLR into power system management as well as reaping the expected benefits.

The potential benefits of DLR have been presented in various publications. Explains that DLR can increase transmission capacity from one region to another [13], which will affect electricity costs and benefit electricity buyers. View the decreases in the optimum total cost of operating the system according to a solution to the traditional problem of unit commitment with DLR [14]. It showed an expansion in wind power usage which increased the carrying capacity of OHTL associated with the wind farm[7]. The same results were found in [15] who reported that with a lower load and a decrease in RES production, more wind energy could be integrated into the grid. The complexity of the problem is reduced by neglecting the differences in the cooling and heating levels of the conductors and assuming the rate of cooling and constant heating of the conductor resulting in a very simplified composition that has been confirmed by simulation [16]. 
Furthermore, combinations that examine the intersection between the dimensions of the comfortable transmission line and the integrity of the RES assume the ideal RES expectations, thereby ignoring the costs resulting from the uncertainty of the RES [15]. Despite these advantages, the main problem with integrating DLR into the OPF is adding nonlinear requirements to SCOPF problems and the system becomes more complex. DLR estimation with SS-HBE requires many parameters which make it very complex. Knowing the value of a solar heat rate is more complicated. As for estimating the solar temperature level, where the inputs are absorption, date, time, latitude, and elevation of data above sea level.

The OPF problem was presented by Carpentier [17] Then, the OPF was studied and widely used in the operation of the electrical network [18]. The OPF algorithm aims to get an ideal solution like (reduce generation costs, increase social welfare, reduce energy loss, etc.). Consequently, the main objective of the OPF is to reduce the generation price of the electrical grid as it has known the traditional OPF which only included sources for the thermal power plant. With the integration and development of RES particularly like wind power[19], it is necessary to incorporate wind energy generation costs into the traditional OPF issue. Several researchers discussed the issue of OPF by incorporating the costs of wind power generation[2025]. The problem of the OPF including the uncertainty of wind power was addressed by the authors, and therefore, the problem is considered a mixed heat and wind generator. Moreover, wind energy integrated with the electric power system is required to significantly influence the planning and operation of the transmission system. The traditional OPF model is not safe from equipment malfunction, so switch attention to an improved model: SCOPF. This pattern ensures that the transmission line can succeed in loading and diverting the energy flow not only under the primary electrical system but also for any emergency caused by the loss of parts of the electrical network, such as the interruption of the power lines. Despite the advantages of this style, one of its drawbacks is the sheer size. The use of artificial intelligence (AI) [26] based technologies in the last two decades has increased to overcome traditional problems that can provide an appropriate solution in a short time compared to customary techniques that are commonly used and increasingly used, such as improving an ant colony (ACO) and improving particles. (PSO); Genetic Algorithm (GA) and Softening Simulation (SA); the benefit of current innovation-based technologies is their faster performance under large fusion problems, such as the SCOPF problem, which is an excellent solution. PSO has been reported as a new guiding strategy by Kennedy and Eberhart which have been used successfully to solve the SCOPF issue.

The main contribution of this work is an integration of DLR within SCOPF methodology based on PSO. Daily data profiles in wind, temperature, load, etc. pose as inputs for this framework that then calculates and applies a DLR to transmission lines and assesses the new state of security of the system. Forecast uncertainty is also considered, which seeks to deal with the required inputs with the most realism possible. The problem is a multi-objective optimization one; the main objective is to maximize the social welfare by minimizing total system operation cost and maximizing the revenue from the energy consumers, whereas the second objective is to minimize the thermal emissions. This paper has the main contributions as follow:

- The thermal properties of monitored OHTL are integrated by a simplified version of the SS-HBE, which conserve the conductor temperature dependence on the conditions of ambient weather.

- The proposed formula takes into account the cost of conventional production, in addition to the costs due to the uncertainty of RES in the electrical system.

- Detailed analysis and discussion about the impacts of observed weather conditions on the production schedules and associated costs are also provided.

- Mathematical validations of the proposed model have also mentioned in detail where the simplicity of the proposed model decreases computational effort when incorporating conductor thermal dynamics in determining the optimal system operating times for conventional and RES.

- The digital simulation on a modified test system illustrates that savings from overcrowding relief by DLR lead to permit more utilization of RES.

The residue of the research is prepared as follows, section II illustrates the IEEE, and the CIGRE model for assessment of the conductor temperature. Mathematical model of SCOPF problems with RES uncertainty costs and model of wind is introduced in section III. The numeral simulation, test system description and impact the weather conditions are illustrated in section IV, while the conclusion of the investigation is outlined is explained in section $\mathrm{V}$.

\section{MODELLING OF DLR}

The correct application of the DLR requires the calculation of the conductor HBE under current meteorological conditions (the maximum transmitted active power or ampacity). There are several ways to calculate the HBE, presented in the literature [27-29]. According to CIGRE and IEEE standard for calculating the current-temperature relationship of conductors, the heat balance can be expressed as in (1) and (2) respectively [29].

$$
\begin{aligned}
& \mathrm{H}_{\mathrm{j}}+\mathrm{H}_{\mathrm{m}}+\mathrm{H}_{\mathrm{i}}+\mathrm{H}_{\mathrm{s}}=\mathrm{H}_{\mathrm{c}}+\mathrm{H}_{\mathrm{r}}+\mathrm{H}_{\mathrm{e}} \\
& \mathrm{H}_{\mathrm{s}}+\mathrm{H}_{\mathrm{j}}=\mathrm{H}_{\mathrm{r}}+\mathrm{H}_{\mathrm{c}}
\end{aligned}
$$

Both CIGRE and IEEE use the same general SS-HBE methodology for determining the maximum current capacity of conductor. IEEE has simplified this equation by eliminating 
three heat balance terms that normally have a very small influence on most ampacity rating calculations. Ampacity will be estimated based on the given meteorological conditions by selecting the maximum conductor temperature. Details on the calculation of each term can be found in [27-29].

Line-rating methodologies, like the IEEE and CIGRE models, have been established to determine the line ampacity based on the thermal heat balance between heat gain and heat loss for conductors. The main thermal contributors are illuminated as shown in Fig. 1. Therefore, the thermal rating of an OHTL is represented as follows [29]:

$$
I_{\max }=\sqrt{\frac{\mathrm{H}_{\mathrm{c}}+\mathrm{H}_{\mathrm{r}}-\mathrm{H}_{\mathrm{s}}}{\mathrm{R}\left(\mathrm{T}_{\mathrm{c}}\right)}}
$$

For simplicity, the DLR model will follow the SS-HBE shown in (3) in this study. The values that are needed for the calculation of ampacity are solar radiation, ambient temperature, wind speed, and wind direction. Making a thermal calculation, ampacity is calculated as the current intensity value which equals conductor temperature to its maximum allowable value as illustrated in Fig. 2.

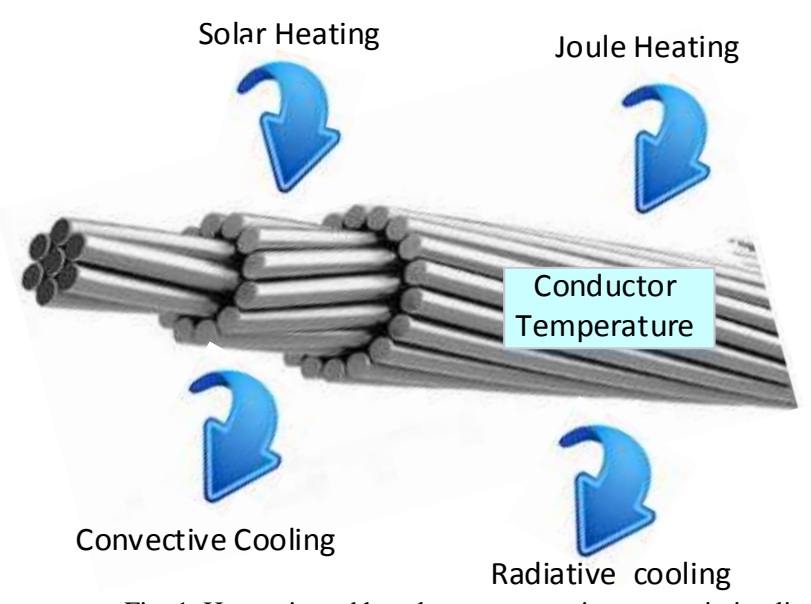

Fig. 1. Heat gain and heat loss processes in a transmission line

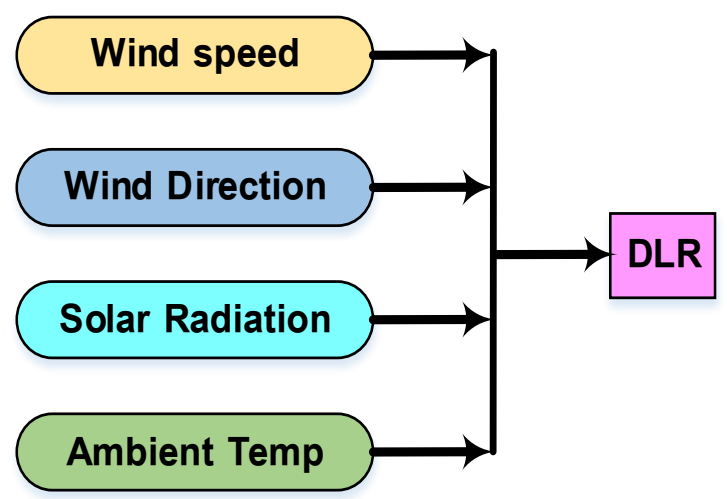

Fig. 2. DLR calculation process in weather system

\section{SCOPF PROBLEM FORMULATION}

The electricity power generation model is described by a minimum cost through the SCOPF problem that takes into consideration bus voltage constraint, generation level limitations, constraints of contingency and constraints of line flow.

\section{A. Mathematical models of the SCOPF problems including RES}

The SCOPF model aims to minimize SW and optimize the steady-state performance of an electrical power system in terms of an objective function while satisfying the system constraints. Mathematically, the SCOPF model is explained as follows [3036].

$$
\begin{aligned}
& \text { Minimize: } f(\mathfrak{x}, \mathrm{u}) \\
& \text { Subject to: }\left\{\begin{array}{c}
\mathcal{G}(\mathfrak{X}, \mathrm{u})=0 \\
, \\
\hbar(\mathfrak{X}, \mathrm{u}) \leq 0
\end{array}\right.
\end{aligned}
$$

In this problem, $\mathfrak{x}$ is defined as a vector belongs to case or dependent variables. $u$ is expressed as a vector of control or independent variables. For this study, the vectors of independent variables and dependent variables are explained below:

$$
\begin{aligned}
u= & {\left[P_{G_{2}}, \ldots, P_{G_{N_{g}}}, P_{w_{1}}, \ldots, P_{w_{N_{\mathrm{w}}}}, V_{G_{1}}, \ldots, V_{G_{N_{g}}}\right] } \\
& {\left[P_{G_{1}}, V_{b_{1}} \ldots, V_{b_{N_{b}}}, Q_{G_{1}}, \ldots, Q_{G_{N_{g}}}, S_{L_{1}}, \ldots, S_{L_{N_{T L}}}\right] }
\end{aligned}
$$

The active output power of the swing generator $\mathrm{P}_{\mathrm{G}_{1}}$ which considers being an independent variable with maximum and minimum constraints.

\section{B. Calculation of wind power probabilities}

The power output of a wind turbine as a function of wind speed $(v)$ can be described as follows [30]:

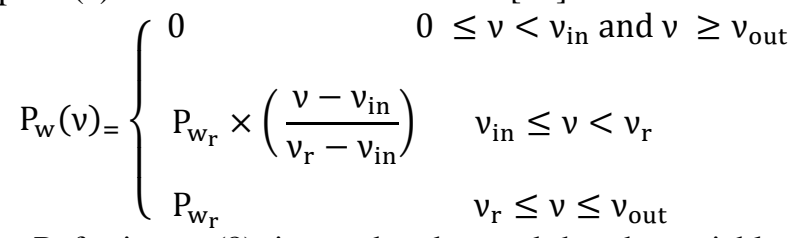

Referring to (8), it may be observed that the variable wind power is discrete in a couple of regions of wind speeds. When wind speed $v$ is below cut-in speed $v_{\text {in }}$ and above cut-out speed $v_{\text {out }}$, the power output is zero. The turbine gives rated power output $\mathrm{P}_{\mathrm{w}_{r}}$ between rated wind speed $v_{\mathrm{r}}$ and $v_{\text {out }}$. For these discrete zones, probabilities of output wind power are given as follows [30]:

$$
\begin{aligned}
& f_{w}\left(\mathrm{P}_{\mathrm{w}}\right)\left\{\mathrm{P}_{\mathrm{w}}=0\right\}=1-\mathrm{e}^{-\left(\frac{v_{\text {in }}}{\mathrm{c}}\right)^{\mathrm{k}}}+\mathrm{e}^{-\left(\frac{v_{\text {out }}}{\mathrm{c}}\right)^{\mathrm{k}}} \\
& f_{w}\left(\mathrm{P}_{\mathrm{w}}\right)\left\{\mathrm{P}_{\mathrm{w}}=\mathrm{P}_{\mathrm{w}_{r}}\right\}=\mathrm{e}^{-\left(\frac{v_{\mathrm{r}}}{\mathrm{c}}\right)^{\mathrm{k}}}-\mathrm{e}^{-\left(\frac{v_{\text {out }}}{\mathrm{c}}\right)^{\mathrm{k}}}
\end{aligned}
$$

The wind turbine power output is continuous between cutin speed $v_{\text {in }}$ and rated speed $v_{\mathrm{r}}$ of wind. The probability for the continuous region is calculated as [30]:

$$
f_{w}\left(P_{w}\right)\left\{0<\mathrm{P}_{\mathrm{w}} \leq \mathrm{P}_{\mathrm{w}_{\mathrm{r}}}\right\}=\left[\frac{\mathrm{k} \psi v_{\mathrm{in}}}{\mathrm{c}}\right] *
$$

$$
\left[\frac{(1+\xi \psi) v_{\text {in }}}{v_{r}-v_{\text {in }}}\right]^{(\mathrm{k}-1)} * \mathrm{e}^{\left(\frac{(1+\xi \psi) v_{\text {in }}}{\mathrm{c}}\right)^{\mathrm{k}}}
$$




\section{The Direct cost of wind power model}

Wind generators need no fossil fuels, unlike thermal generators. The direct cost of the wind power model is expressed as a function of the scheduled wind power.

$$
\mathrm{C}_{\mathrm{w}, \mathrm{i}}=\mathrm{d}_{\mathrm{i}} \mathrm{P}_{\mathrm{ws}, \mathrm{i}} f_{\mathrm{W}}\left(\mathrm{P}_{\mathrm{w}, \mathrm{i}}\right)
$$

\section{Uncertainties costs for the wind power model}

If the energy actually delivered from the wind farms is less than the expected value, this situation shows an overestimation of power from the uncertain resources. This reserve cost is defined as the overestimation of available wind power in (13).

$$
C_{R w, i}=k_{R w, i} \int_{0}^{P_{w s, i}}\left(P_{w s, j}-P_{w, i}\right) f_{w}\left(P_{w, i}\right) d P_{w, i}
$$

If the delivered actual power from the wind farm is greater than the expected value, the wind power source is underestimated in such a case .penalty cost for the wind farm is shown in (14)

$$
\mathrm{C}_{\mathrm{Pw}, \mathrm{i}}=\mathrm{k}_{\mathrm{Pw}, \mathrm{i}} \int_{\mathrm{P}_{\mathrm{w} s, \mathrm{i}}}^{\mathrm{P}_{\mathrm{wr}, \mathrm{i}}}\left(\mathrm{P}_{\mathrm{w}, \mathrm{i}}-\mathrm{P}_{\mathrm{ws}, \mathrm{i}}\right) \mathrm{f}_{\mathrm{w}}\left(\mathrm{P}_{\mathrm{w}, \mathrm{i}}\right) \mathrm{dP}_{\mathrm{w}, \mathrm{i}}
$$

The total wind power generation cost calculate as follows:

$$
\mathrm{C}_{\mathrm{T}}\left(\mathrm{P}_{\mathrm{ws}, \mathrm{i}}\right)=\sum_{\mathrm{i}=1}^{\mathrm{N}_{\mathrm{w}}}\left[\mathrm{C}_{\mathrm{w}, \mathrm{i}}+\mathrm{C}_{\mathrm{Rw}, \mathrm{i}}+\mathrm{C}_{\mathrm{Pw}, \mathrm{i}}\right]
$$

\section{The Fuel cost model of thermal Generation}

The cost model of thermal generators with fossil fuel is shown in (16).

$$
\mathrm{C}_{\mathrm{T}}\left(\mathrm{P}_{\mathrm{Gi}}\right)=\sum_{\mathrm{i}=1}^{\mathrm{N}_{\mathrm{g}}} \mathrm{a}_{\mathrm{i}} P_{\mathrm{G}_{i}}^{2}+\mathrm{b}_{\mathrm{i}} \mathrm{P}_{\mathrm{G}_{i}}+\mathrm{C}_{\mathrm{i}}
$$

\section{- Energy Buying Revenue}

The goal of purchasing energy to demand is to maximize the profit (which is the cost of purchasing energy), which can be expressed as in (17).

$$
\mathrm{R}_{\mathrm{T}}\left(\mathrm{P}_{\mathrm{D}}\right)=\sum_{i=1}^{\mathrm{N}_{\mathrm{d}}} \lambda_{i} P_{D i}
$$

LMP is composed of three elements: energy price, loss price, and congestion price. After satisfying the power flow constraint, the congestion price is zero, and therefore the LMP at each bus is composed of the marginal price of generation at the reference bus and the marginal loss price at that node. LMP at each bus is mathematically defined as the dual variable of the power balance constraint at that node.

\section{- Emission and carbon Tax model}

It is well known that generating power from traditional sources (thermal energy) of energy emit harmful gases into the environment. The emission of $\mathrm{SO}_{\mathrm{x}}, \mathrm{NO}_{\mathrm{x}}, \mathrm{CO}_{\mathrm{x}}$ raises with an increase in generated power (in p.u, MW) from thermal generators following the relation in (18). Emission in tones per hour (ton/hour) is calculated by:

$$
\begin{gathered}
C_{T}(E m)=\sum_{i=1}^{N_{g}}\left[\left(\alpha_{i}+\beta_{i} P_{G_{i}}+\gamma_{i} P_{G_{i}}^{2}\right) \times 0.01\right. \\
\left.+\omega_{i} e^{\left(\mu_{i} P_{G_{i}}\right)}\right]
\end{gathered}
$$

\section{Objective Functions}

The objective function of the SCOPF problem includes reduction of SW and thermal emissions. The SW consist of the variance between the cost of thermal generators, the wind generator and the income from consumer purchase explained in (19) and (20):

$$
\begin{aligned}
& \mathrm{SW}=\mathrm{C}_{\mathrm{T}}\left(\mathrm{P}_{\mathrm{Gi}}\right)+\mathrm{C}_{\mathrm{T}}\left(\mathrm{P}_{\mathrm{ws}, \mathrm{i}}\right)-\mathrm{R}_{\mathrm{T}}\left(\mathrm{P}_{\mathrm{D}}\right) \\
& \text { Minimization } \Rightarrow \mathrm{F}=\mathrm{SW}+\mathrm{C}_{\mathrm{T}}(\mathrm{Em})
\end{aligned}
$$

\section{Equality and inequality constraints}

Equality constraints of the system are described as equations of power flow. Reactive and active power balance equations can be defined in (21) and (22) as follows:

$$
\begin{gathered}
\mathrm{P}_{\mathrm{G}_{\mathrm{i}}}-\mathrm{P}_{\mathrm{Di}}-\mathrm{V}_{\mathrm{i}} \sum_{\mathrm{j}=1}^{\mathrm{NB}} \mathrm{V}_{\mathrm{j}}\left[\mathrm{g}_{\mathrm{ij}} \cos \left(\delta_{\mathrm{ij}}\right)+\mathrm{b}_{\mathrm{ij}} \sin \left(\delta_{\mathrm{ij}}\right)\right]=0 \\
\mathrm{Q}_{\mathrm{G}_{\mathrm{i}}}-\mathrm{Q}_{\mathrm{Di}}-\mathrm{V}_{\mathrm{i}} \sum_{\mathrm{j}=1}^{\mathrm{NB}} \mathrm{V}_{\mathrm{j}}\left[\mathrm{g}_{\mathrm{ij}} \sin \left(\delta_{\mathrm{ij}}\right)-\mathrm{b}_{\mathrm{ij}} \cos \left(\delta_{\mathrm{ij}}\right)\right]=0
\end{gathered}
$$

The inequality constraints of the electrical system are shown in (23-30).

$$
\begin{array}{ll}
\mathrm{P}_{\mathrm{Gi}}^{\min } \leq \mathrm{P}_{\mathrm{Gi}} \leq \mathrm{P}_{\mathrm{Gi}}^{\max } & \forall \mathrm{i} \in \mathrm{N}_{\mathrm{g}} \\
\mathrm{P}_{\mathrm{ws}, \mathrm{i}}^{\min } \leq \mathrm{P}_{\mathrm{ws}, \mathrm{i}} \leq \mathrm{P}_{\mathrm{ws}, \mathrm{j}}^{\max } & \forall \mathrm{i} \in \mathrm{N}_{\mathrm{w}} \\
\mathrm{Q}_{\mathrm{Gi}}^{\min } \leq \mathrm{Q}_{\mathrm{Gi}} \leq \mathrm{Q}_{\mathrm{Gi}}^{\max } & \forall \mathrm{i} \in \mathrm{N}_{\mathrm{g}} \\
\mathrm{Q}_{\mathrm{ws}, \mathrm{i}}^{\min } \leq \mathrm{Q}_{\mathrm{ws}, \mathrm{i}} \leq \mathrm{Q}_{\mathrm{ws}, \mathrm{i}}^{\max } & \forall \mathrm{i} \in \mathrm{N}_{\mathrm{w}} \\
\mathrm{V}_{\mathrm{Gi}}^{\min } \leq \mathrm{V}_{\mathrm{Gi}} \leq \mathrm{V}_{\mathrm{Gi}}^{\min } & \forall \mathrm{i} \in \mathrm{N}_{\mathrm{L}} \\
\mathrm{V}_{\mathrm{L}}^{\min } \leq \mathrm{V}_{\mathrm{L}} \leq \mathrm{V}_{\mathrm{L}}^{\max } & \forall \mathrm{i} \in \mathrm{N}_{\mathrm{TL}} \\
\mathrm{S}_{\mathrm{Li}} \leq \mathrm{S}_{\mathrm{Li}}^{\max } & \\
\mathrm{Ta}_{\mathrm{i}, \mathrm{j}} \leq \mathrm{Tc}_{\mathrm{i}, \mathrm{j}} \leq \mathrm{Tc}_{\mathrm{i}, \mathrm{j}}^{\max } &
\end{array}
$$

\section{CASE STUDIES AND RESULTS}

The performance of the SCOPF formulation with RES and DLR described in sections II and III is solved in MATLAB ${ }^{\circledR}$ using the PSO technique.

\section{A. The modified test system}

The test system used is the modified IEEE 30-bus test system shown in Fig. 3. It has 41 branches, and 4 transformers. It has six thermal generators and three wind generators, where cost coefficients of emission and thermal are listed in tables 1 and 2 respectively. The load and branch data are given in [38]. The sites of the wind farms were randomly chosen as mentioned 
in [29]. All the conductor's data are taken from [39]. This test system is divided into three zones; each zone has different climatic conditions; as shown in the figures. Simulations are carried out using weather data recorded at three different sites in Egypt.

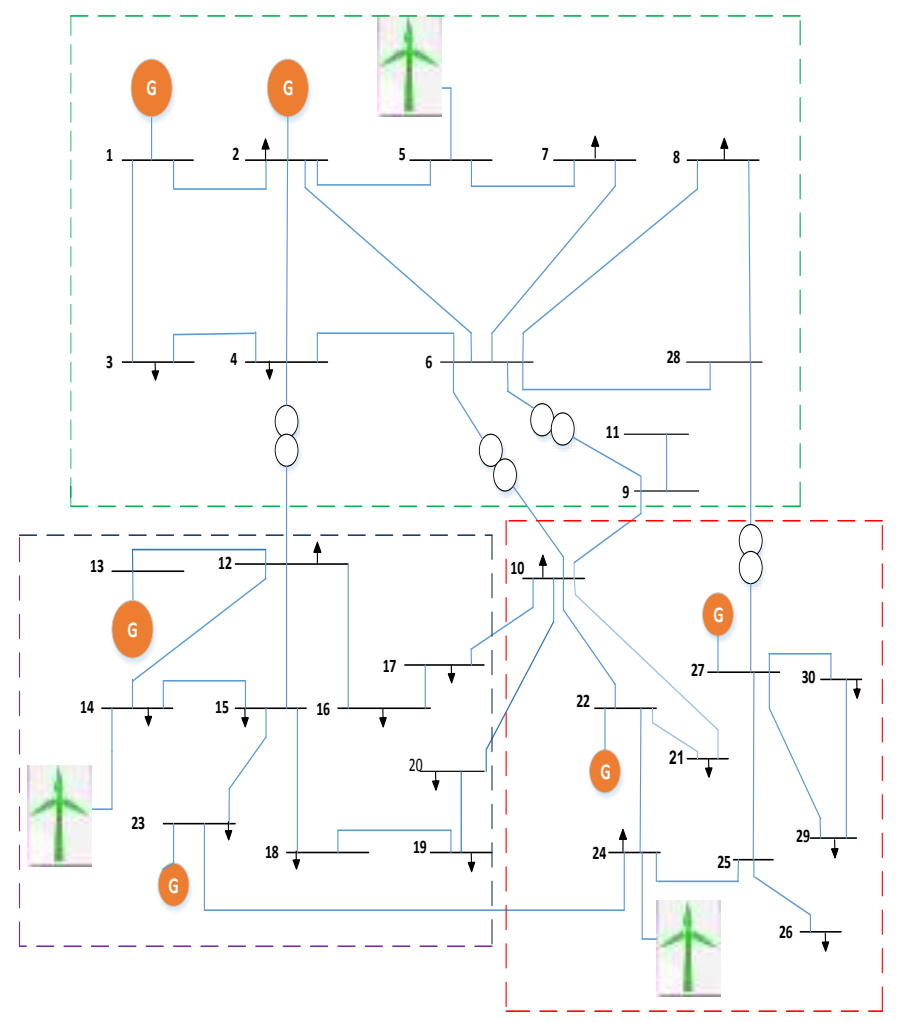

Fig. 3. Single Line Diagram of Modified IEEE 30 Bus Test System

TABLE 1

\begin{tabular}{c||c||c||c||c||c}
\multicolumn{5}{c}{ Emission coefficients of thermal generators [30, 33, 36] } \\
\multirow{2}{*}{ Bus No } & \multicolumn{4}{|c}{ Emission Coefficients } \\
\cline { 2 - 5 } & $\boldsymbol{\alpha}$ & $\boldsymbol{\beta}$ & $\boldsymbol{\gamma}$ & $\boldsymbol{\mu}$ & $\boldsymbol{\omega}$ \\
\hline 1 & 4.091 & -5.554 & 6.490 & 2.857 & 0.000200 \\
\hline 2 & 2.543 & -6.047 & 5.638 & 3.333 & 0.000500 \\
\hline 13 & 4.258 & -5.094 & 4.586 & 8.000 & 0.000001 \\
\hline 22 & 5.426 & -3.550 & 3.380 & 2.000 & 0.002000 \\
\hline 23 & 4.258 & -5.094 & 4.586 & 8.000 & 0.000001 \\
\hline 27 & 6.131 & -5.555 & 5.151 & 6.667 & 0.000010
\end{tabular}

TABLE 2

\begin{tabular}{c|c|c|c|c|c}
\multirow{2}{*}{ Bus No } & \multirow{2}{*}{$\boldsymbol{P}_{\boldsymbol{G}}^{\text {Max }}$} & $\boldsymbol{P}_{\boldsymbol{G}}^{\text {Min }}$ & \multicolumn{3}{|c}{ Cost Coefficients } \\
\cline { 4 - 6 } & & & $\boldsymbol{a}_{\boldsymbol{i}}$ & $\boldsymbol{b}_{\boldsymbol{i}}$ & $\boldsymbol{c}_{\boldsymbol{i}}$ \\
\hline \hline 1 & 200 & 50 & 0.100 & 10.000 & 0 \\
\hline \hline 2 & 80 & 20 & 0.088 & 8.750 & 0 \\
\hline \hline 13 & 50 & 15 & 0.125 & 15.000 & 0 \\
\hline \hline 22 & 35 & 10 & 0.313 & 5.000 & 0 \\
\hline \hline 23 & 30 & 10 & 0.100 & 15.000 & 0 \\
\hline \hline 27 & 40 & 12 & 0.042 & 16.250 & 0
\end{tabular}

\section{B. Parameters of wind Model}

The wind power generator connected to bus 5 is an equivalent of a wind farm containing 15 units, whereas the wind generator at bus 14 is the aggregate of 10 units, and that connected to bus 24 is the equivalent of 5 units. Each wind generating unit has a rated output power of $3 \mathrm{MW}$ and actual output power from a wind turbine depends on the wind and characteristic wind speeds of, $v_{\text {in }}=5 \mathrm{~m} / \mathrm{s}, v_{\mathrm{r}}=16 \mathrm{~m} / \mathrm{s}$, and $v_{\text {out }}=25 \mathrm{~m} / \mathrm{s}$. In this paper, the power output probability distribution of wind farm is installed based on the Weibull distribution of the wind speed [30] and wind turbine model expressed by function approximation. Fig. 4 gives the Weibull distribution with shape factor (k) and scale factor (c) [30]. By applying MATLAB ${ }^{\circledR}$ simulation, the frequency distribution of wind speed can be obtained as illustrated in Fig. 4.

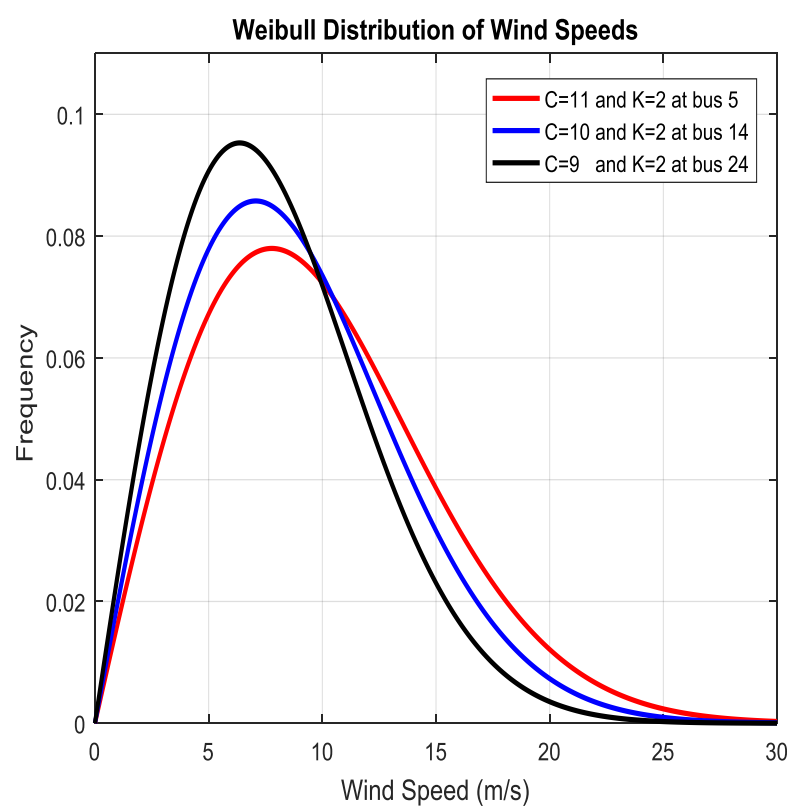

Fig. 4: Distribution of wind speed at bus 5, 14 and 24

\section{Daily loads curve}

In this paper, daily load curves are used in the system [40]. The system loads are supposed to be classified into three collections as evidenced in Fig. 5, where the load for group 3 is fixed while groups 1 and 2 are variable per hour (24 hours).

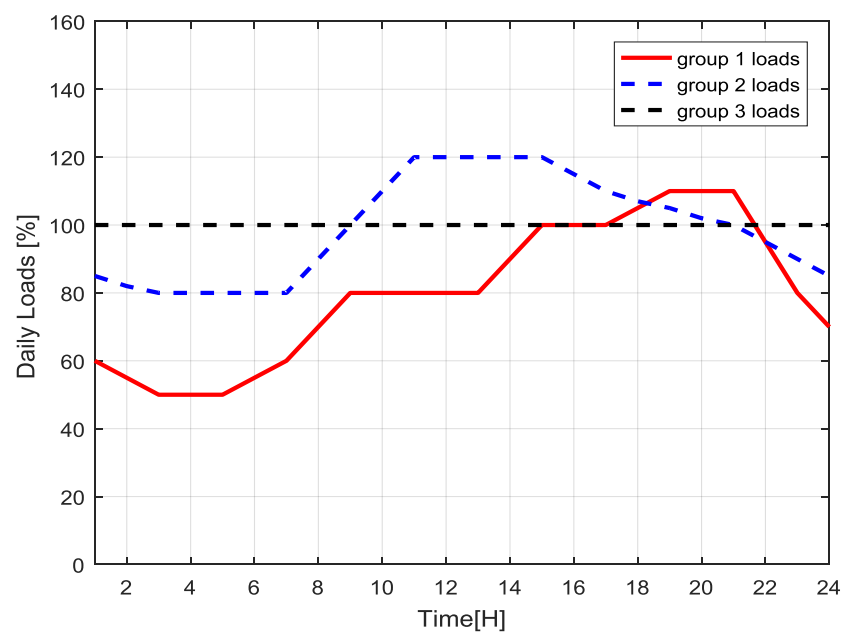

Fig. 5: Daily load curve 


\section{Effect of weather parameters online rating}

DLR change broadly depending on the values of the climate parameters. To explain the reliance capacity of climate parameters, three types of conductors are applied in three areas on the modified IEEE 30 bus standard test system. The threeconductor data whose parameters were presented in Table 3 are used. Fig. 6 displays how the value of capacity change with the different climate parameters and the base weather parameter (worst case as reference) values are shown in Table 4.

The capacity for ACSR $160 \mathrm{~mm}^{2}$ increases from the static rating of $471 \mathrm{~A}$ for a wind speed of $0.5 \mathrm{~m} / \mathrm{s}$ to $931 \mathrm{~A}$ for a wind speed of $6 \mathrm{~m} / \mathrm{s}$ (a $98 \%$ raise), while the ampacity for $810 \mathrm{~mm}^{2}$ TACSR and 329AL59 increase (97\% and 87\% respectively) at the same of temperature of ambient and wind speed.

TABLE 3

Parameters for three different conductors [39]

\begin{tabular}{|c|c|c|c|}
\hline Property[units] & $\begin{array}{c}160 \mathrm{~mm}^{2} \\
\text { ACSR }\end{array}$ & $\begin{array}{l}810 \mathrm{~mm}^{2} \\
\text { TACSR }\end{array}$ & 329AL59 \\
\hline No Layers of Aluminum & 2.0000 & 3.0000 & 2.0000 \\
\hline $\begin{array}{l}\text { Overall diameter of Conductor D } \\
{[\mathrm{mm}]}\end{array}$ & 18.200 & 38.400 & 23.600 \\
\hline $\begin{array}{l}\text { Outer layer diameter of conductor } \\
\mathrm{d}[\mathrm{mm}]\end{array}$ & 2.6000 & 4.8000 & 3.2600 \\
\hline Resistance at ref Temp $\mathrm{R}_{\mathrm{ac}}^{\mathrm{ref}}\left[\frac{\Omega}{\mathrm{Km}}\right]$ & 0.1711 & 0.0373 & 0.0993 \\
\hline $\begin{array}{l}\text { Temp coefficient of resistance } \\
\alpha\left[\text { per }^{\circ} \mathrm{C}\right]\end{array}$ & 0.0038 & 0.0036 & 0.0038 \\
\hline Factor of absorptivity $\alpha_{s}$ & 0.5000 & 0.5000 & 0.5000 \\
\hline Factor of emissivity $\varepsilon$ & 0.5000 & 0.5000 & 0.5000 \\
\hline $\begin{array}{l}\text { Maximum temp of Conductor } \\
\mathrm{T}_{\max }\left[{ }^{\circ} \mathrm{C}\right]\end{array}$ & 90.000 & 150.00 & 150.00 \\
\hline $\mathrm{SLR}[\mathrm{A}]$ at $0.5 \mathrm{~m} / \mathrm{s}$ and $\mathrm{Ta}=40\left[{ }^{\circ} \mathrm{C}\right]$ & 471.00 & 1900.0 & 995.00 \\
\hline
\end{tabular}

The effects of weather parameters on transmission line loadability for three types of conductors are illustrated in Fig.3.6. Wind speed is shown the largest overall percentage variation in comparison to the other parameters. On the other hand, the temperature of ambient has shown a downward trend for ampacity because of the temperature of the ambient raised (10 to 50). This is relevant to the truth that convective cooling and irradiative cooling are immediately linked to the variation between the temperature of conductor and the temperature of ambient typically, wind speed is extremely changeable, and steady wind speed is very unlikely. Sensitiveness analysis has shown that with the richness of high wind speed, convection cooling is at its highest and does in fact drive the capacity of the conductor.

TABLE 4

Base values for weather parameters

\begin{tabular}{l||c}
\multicolumn{1}{c||}{$\begin{array}{c}\text { Base values for weather parameters } \\
\text { Items }\end{array}$} & Value \\
\hline Ambient temperature $\mathrm{Ta}\left[{ }^{\circ} \mathrm{C}\right]$ & 40.00 \\
\hline Wind speed $\mathrm{V}[\mathrm{m} / \mathrm{s}]$ & 0.500 \\
\hline Wind Speed direction $\delta\left[^{\circ}\right]$ & 45.00 \\
\hline solar radiation $\mathrm{S}\left[\mathrm{W} / \mathrm{m}^{2}\right]$ & 1000 \\
\hline Relative air density & 1.000 \\
\hline
\end{tabular}
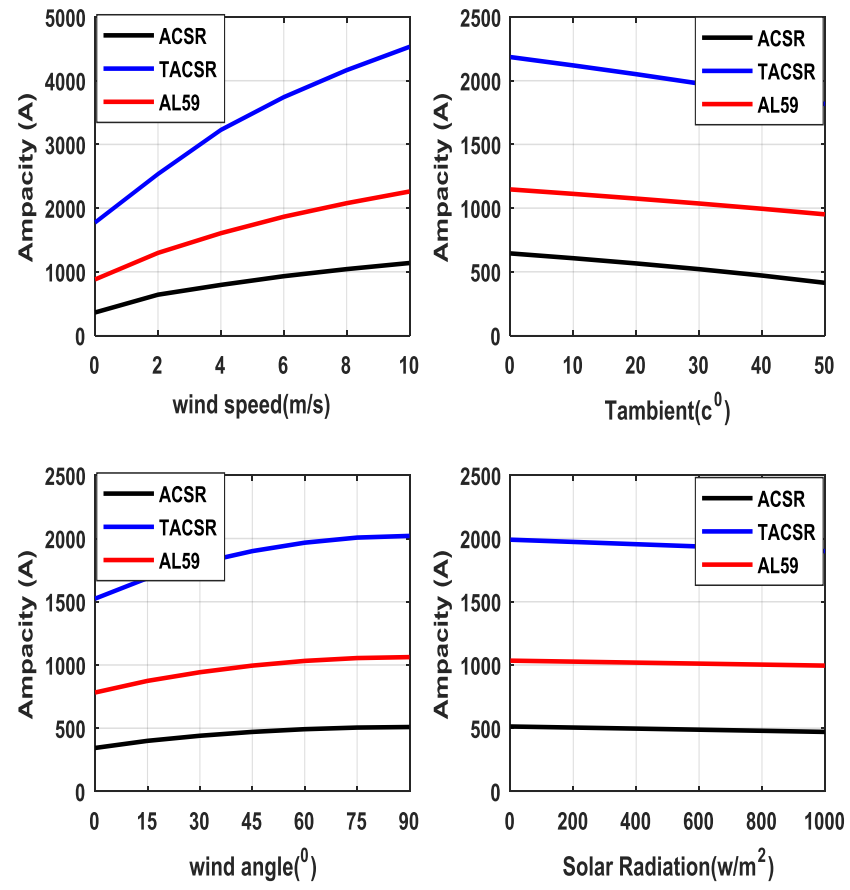

Fig.6.conductor's ampacity Variation with different weather parameters

\section{E. Numerical Results}

In this section, the SCOPF/PSO optimal solution obtained from DLR and SLR is compared as illustrated in Table 5. The RES scheduled generation increases on buses 5 and 14, while decreases on bus 24 . The amount of increase in RES schedule on buses 5 and 14 is greater than the decrease in bus 24 which leads to a total increase in scheduled RES generation. The cost of wind and traditional power generation depends on LMPs in the system and its proximity to loading centers. The scheduled RES generation on buses 5 and 14 increases with decreasing LMPs on these buses, while scheduled RES generation on bus 24 decreases with increasing LMPs on this bus. Therefore, thermal generation decreases while the generation from RES increases at the same value approximately. Also, Fig.7 illustrates the difference in the scheduled generation between the two cases.

TABLE 5

\begin{tabular}{c||c||c||c}
\multicolumn{4}{c}{ Optimal generation schedules per day } \\
Energy /day & DLR & SLR & diff \\
\hline $\mathbf{P}_{\mathbf{G} 1}$ & 818.540 & 753.780 & 64.76 \\
\hline $\mathbf{P}_{\mathbf{G} 2}$ & 980.15 & 982.000 & -1.85 \\
\hline $\mathbf{P}_{\mathbf{G} 13}$ & 708.570 & 737.400 & -28.83 \\
\hline $\mathbf{P}_{\mathbf{G} 22}$ & 503.270 & 533.560 & -30.29 \\
\hline $\mathbf{P}_{\mathbf{G} 23}$ & 498.080 & 496.410 & 1.670 \\
\hline $\mathbf{P}_{\mathbf{G} 27}$ & 614.390 & 712.290 & -97.90 \\
\hline Total thermal $\mathbf{P}_{\mathbf{G}}$ & $\mathbf{4 1 2 3 . 0 0}$ & $\mathbf{4 2 1 5 . 4 4}$ & $\mathbf{- 9 2 . 4 4}$ \\
\hline $\mathbf{P}_{\mathbf{w} 5}$ & 760.21 & 704.560 & 55.65 \\
\hline $\mathbf{P}_{\mathbf{w} 14}$ & 438.58 & 395.410 & 43.17 \\
\hline $\mathbf{P}_{\mathbf{w} 24}$ & 211.69 & 217.990 & -6.300 \\
\hline Total wind & $\mathbf{1 4 1 0 . 4 8}$ & $\mathbf{1 3 1 7 . 9 6}$ & $\mathbf{9 2 . 5 2}$
\end{tabular}




\section{$\square$ DLR $\square$ SLR}

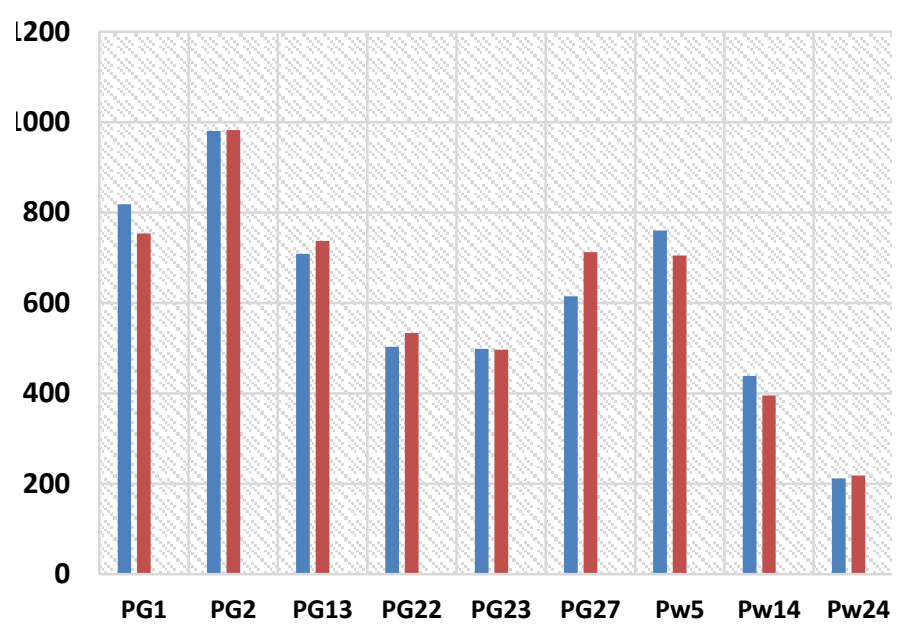

Fig. 7. Optimal generation schedules per day

Table 6 illustrates the comparison between this paper and the results in [41]. The results were compared in terms of the scheduled generation, losses, total generation costs, emissions, and social welfare results, where these proposed results are calculated at one hour and compare them with results in [41]. It has been shown from the results of this table that the thermal generation in the case of the DLR is less than the thermal generation in the case of the SLR by $3.94 \%$ while in [41] the percentage is $3.22 \%$. The generation from RES is increased by $6.94 \%$ but the percentage in [41] is $7.4 \%$. Also shown from Table 6 that the total costs in this paper are lower compared with [41]. Also, these proposed results illustrate the emission in DLR is lower than SLR while the social welfare is higher in the case of DLR compared with SLR.

TABLE 6

Comparison between the proposed method and results of ref. [41]

\begin{tabular}{|c|c|c|c|c|c|c|}
\hline & \multicolumn{3}{|c|}{ Proposed } & \multicolumn{3}{|c|}{ Ref. [41] } \\
\hline & DLR & SLR & diff & DLR & SLR & diff \\
\hline$P_{\mathrm{G} 1}$ & 50.3 & 58.3 & -8.0 & 47.0 & 62.1 & -15.1 \\
\hline $\mathbf{P}_{\mathrm{G} 2}$ & 58.1 & 73.2 & -15.1 & 60.9 & 78.2 & -17.3 \\
\hline $\mathbf{P}_{\mathrm{G} 13}$ & 17.6 & 28.0 & -10.5 & 17.6 & 27.0 & -9.3 \\
\hline $\mathbf{P}_{\mathrm{G} 22}$ & 21.5 & 8.4 & 13.1 & 23.1 & 6.6 & 16.5 \\
\hline $\mathbf{P}_{\mathrm{G} 23}$ & 18.8 & 11.9 & 6.9 & 17.6 & 10.9 & 6.7 \\
\hline $\mathbf{P}_{\mathrm{G} 27}$ & 31.2 & 25.8 & 5.5 & 37.9 & 26.1 & 11.8 \\
\hline $\begin{array}{l}\text { Total } \\
\text { thermal }\end{array}$ & 197.5 & 205.6 & -8.1 & 204.1 & 210.9 & -6.8 \\
\hline $\mathbf{P}_{\mathrm{w5}}$ & 36.2 & 36.3 & -0.1 & 16.4 & 17.7 & $\begin{array}{l}-1.2 \\
\end{array}$ \\
\hline $\mathbf{P}_{\mathrm{w} 14}$ & 28.2 & 30.3 & -2.0 & 32.9 & 34.3 & -1.5 \\
\hline $\mathbf{P}_{\mathrm{w} 24}$ & 49.5 & 40.0 & 9.5 & 49.3 & 39.8 & 9.5 \\
\hline Total wind & 114.0 & 106.6 & 7.4 & 98.6 & 91.8 & 6.7 \\
\hline $\begin{array}{l}\text { Total } \\
\text { losses } \\
\end{array}$ & 4.2 & 5.1 & -0.8 & - & - & - \\
\hline Wind cost & 945.6 & 780.3 & 165.3 & 823.3 & 725.3 & 98.0 \\
\hline $\begin{array}{l}\text { thermal } \\
\text { cost }\end{array}$ & 2815.2 & 3250.4 & -435.1 & 3112 & $\begin{array}{l}3399 . \\
5\end{array}$ & -287.2 \\
\hline Total cost & 3760.8 & 4030.6 & -269.8 & 3935 & 4124 & -189.2 \\
\hline $\begin{array}{l}\text { Emission } \\
\text { (ton/hr) }\end{array}$ & 0.44 & 0.59 & -0.15 & - & - & - \\
\hline $\begin{array}{l}\text { Social } \\
\text { welfare }\end{array}$ & -10340.4 & -9865.4 & -475 & - & - & - \\
\hline
\end{tabular}

The corresponding total operation costs are shown in table 7, also this table presents SW, losses and emission levels. Looking at the table shown, the optimum cost of generation based on DLR is lowered compared to SLR by1000.51\$. Moreover, it was noted that the objective function value reduction was due to a decrease in the cost of conventional generation as a result of the use of a DLR which depending on weather conditions in real-time, as well as there is an increase in output energy for all wind generators, and decreasing costs, and less spillage energy. The obtained results using DLR for maximizing SW are presented in Table 6. In this case, SW raised from $-225817 \$ /$ day to $-226384 \$ /$ day. Also, the total generation costs are decreased from $65447.03 \$$ /day to 64446.52 $\$ /$ day and the total losses are decreased by $2.6 \% \mathrm{Mwh}$ in the DLR case compared with SLR. The second objective is achieved where the emission level is decreased in the case of DLR by $20.4 \%$ compared with SLR.

TABLE 7

Total costs for optimal generation, Social welfare, losses and emission level during 24 hours

\begin{tabular}{l||c||c||c}
\multicolumn{1}{c||}{ Item } & DLR & SLR & diff \\
\hline Total losses & 86.21000 & 88.51000 & -2.30000 \\
\hline Wind generation cost & 22094.64 & 25398.56 & -3333.92 \\
\hline Total Generation cost & 64446.52 & 65447.03 & -1000.51 \\
\hline Social welfare & -226384.0 & -225817.0 & -567.000 \\
\hline Emission levels(ton/day) & 159.84 & 163.02 & -3.18
\end{tabular}

Table 8 shows a comparison among transmission lines ampacity in the case of DLR and SLR in the three different zones. From the results indicated, the value of lines ampacity in the case of DLR is greater than compared as the SLR, and then these results demonstrate decreasing in system operation cost and wind power curtailment.

TABLE 8

Transmission Line ampacity in three groups

\begin{tabular}{|c|c|c|c|c|c|c|}
\hline \multirow{2}{*}{ Hour } & \multicolumn{3}{|c|}{ SLR } & \multicolumn{3}{|c|}{ DLR } \\
\hline & $I_{\max 1}$ & $\mathbf{I}_{\max 2}$ & $\mathbf{I}_{\max 3}$ & $\mathbf{I}_{\max 1}$ & $I_{\max 2}$ & $I_{\max 3}$ \\
\hline 1 & 135 & 114.94 & 155.51 & 218.97 & 452.17 & 234.91 \\
\hline 2 & 118.05 & 95.25 & 127.82 & 224.48 & 445.86 & 241.16 \\
\hline 3 & 122.01 & 109.35 & 144.07 & 223.76 & 448.03 & 221.84 \\
\hline 4 & 121.58 & 91.05 & 130.02 & 214.22 & 473.29 & 233.18 \\
\hline 5 & 109.34 & 157.01 & 145.44 & 209.46 & 455.38 & 242.5 \\
\hline 6 & 104.74 & 80.71 & 137.83 & 225.51 & 448.26 & 223.67 \\
\hline 7 & 135.73 & 93.1 & 128.62 & 225.28 & 451.37 & 234.39 \\
\hline 8 & 158.2 & 126.45 & 159.42 & 249.57 & 470.14 & 231.68 \\
\hline 9 & 177.65 & 109.22 & 177.46 & 257.28 & 452.61 & 254.21 \\
\hline 10 & 193.72 & 145.15 & 211.37 & 304.8 & 461.92 & 266.92 \\
\hline 11 & 163.88 & 180.56 & 220.77 & 249.64 & 487.54 & 272.72 \\
\hline 12 & 196.56 & 187.45 & 220.29 & 257.39 & 448.89 & 273.37 \\
\hline 13 & 175.39 & 180.69 & 226.87 & 259.81 & 447.83 & 276.76 \\
\hline 14 & 182.82 & 160.75 & 225.15 & 273.41 & 506.27 & 269.03 \\
\hline 15 & 193.83 & 212.89 & 221.21 & 280.23 & 492.34 & 260.29 \\
\hline 16 & 205.19 & 233.42 & 224.03 & 277.23 & 464.69 & 272.61 \\
\hline 17 & 194.52 & 201.27 & 213.42 & 276.31 & 477.88 & 254.4 \\
\hline
\end{tabular}




\begin{tabular}{l||c||c||c||c||c||c}
$\mathbf{1 8}$ & 205.87 & 212.3 & 217.57 & 287.74 & 472.36 & 254.88 \\
\hline $\mathbf{1 9}$ & 204.64 & 220.33 & 192.49 & 292.22 & 483.02 & 263.68 \\
\hline $\mathbf{2 0}$ & 212.09 & 201.11 & 193.03 & 300.97 & 502.52 & 282.01 \\
\hline $\mathbf{2 1}$ & 215.43 & 224.69 & 188.73 & 293.57 & 467.52 & 262.37 \\
\hline $\mathbf{2 2}$ & 190.91 & 100.22 & 159.21 & 301.04 & 492.54 & 264.91 \\
\hline $\mathbf{2 3}$ & 179.15 & 193.17 & 148.3 & 259.78 & 453.33 & 242.17 \\
\hline $\mathbf{2 4}$ & 150.23 & 131.22 & 141.68 & 235.63 & 448.76 & 260.65
\end{tabular}

\section{CONCLUSION}

This paper developed a SCOPF formulation, takes into consideration power output from RES and specific maximum limits for the temperature of the conductor. Three types of conductors with different parameters are placed in three different regions in the electrical network to explain the effect of changing weather parameters on the conductor ampacity based on the daily load curve. Wind speed parameter is the greatest impact on the change of the conductor ampacity compared to other weather parameters. Also, the $160 \mathrm{~mm}^{2}$ conductor changes more by increasing wind speed compared to the other types. Numerical emulations on the modified 30 bus test system

were utilized to illuminate that the surrounding climate conditions around conductors and uncertainty costs of RES have influenced on the optimal timetables obtained from the solution of the SCOPF issue. A comparison was made between DLR and SLR to study the change of ampacity and calculate the generation capacity in both cases. This paper proved that with the changing weather parameters, this led to a reduction in thermal generation, sequentially a reduction in harmful gas emissions and opportunities become available to increase production capacity RES. The savings from the reduced system crowding can be utilized to take in more uncertainty in power generation because of RES (i.e. a minimization in costs of conventional generation increases costs of RES uncertainty). This result turns into an improvement in RES usage. On the other hand, the research made some other profits, which are the low power losses, increase in social welfare by the reduction in total generation cost, and minimization in emission levels compared with SLR.

\section{REFERENCES}

[1] Renewables 2019 Global Status Report, 2019, https://www.ren21.net-/wpcontent/uploads/2019/05/gsr_2019_full_report_en.pdf.

[2] R. Wang, P. Wang, G. Xiao, and S. Gong, "Power demand and supply management in micro grids with uncertainties of renewable energies," Int. J. Elect. Power Energy Syst., vol. 63, pp. 260-269, Dec. 2014.

[3] Z. Rejc, and M. Čepin, "Estimating the additional operating reserve in power systems with installed renewable energy sources," Int. J. Elect. Power Energy Syst., vol. 62, pp. 654-664, Nov. 2014.

[4] J. Heckenbergerovà, P. Musilek, and K. Filimonenkov, "Quantification of gains and risks of static thermal rating based on typical meteorological year," Int. J. Elect. Power Energy Syst., vol. 44, no. 1, pp. 227-235, Jan. 2013.

[5] T. Krontiris, A. Wasserrab, and G. Balzer, "Weather-based loading of overhead lines consideration of conductor's heat capacity," in Proc. 2010 Modern Elect. Power Syst. Conf., Wroclaw- Poland, pp. 1-8, Sept. 2010.

[6] G. Kosec, M. Maksić, and V. Djurica, "Dynamic thermal rating of power lines - model and measurements in rainy conditions," Int. J. Elect. Power Energy Syst., vol. 91, pp. 222-229, Apr. 2017.

[7] M. Simms, and L. Meegahapola, "Comparative analysis of dynamic line rating models and feasibility to minimize energy losses in wind rich power networks," Int. J. Energy Conv. Management, vol. 75, pp. 11-20, 2013.
[8] S. Abbott, S. Abdelkader, L. Bryans, and D. Flynn, "Experimental validation and comparison of IEEE and CIGRE dynamic line models," In Proc. 45th. int. Univ. Power Eng. Conf., Cardiff -Wales -UK. pp. 1-5, Sept. 2010.

[9] S. Abdelkader, D. Morrow, J. Fu's, and S. Abbot "Partial least squares model for dynamic rating of overhead lines in wind intensive areas based on field measurements," J. Renewable Sust. Energy, vol. 5, no.6, Nov. 2013.

[10] S. Abdelkader, J. Fu's, S. Abbot, and B. Fox "Dynamic monitoring of overhead line ratings in wind intensive areas," in proc. European wind Energy Conf.2009, March 2009.

[11] J. Fu's, S. Abdelkader, and D. Morrow, "Partial least squares modelling for dynamic overhead line ratings," In Proc. IEEE. Power Tech. conf., Trondheim, Norway, pp.1-6, June 2011.

[12] CIGRE. Working Group "Thermal behaviour of overhead conductors," Aug. 2002.

[13] S. Uski, "Estimation method for dynamic line rating potential and economic benefits," Int. J. Elect. Power Energy Syst., vol. 65, pp. 76-82, Feb. 2015.

[14] M. Nick, O. Alizadeh-Mousavi, R. Cherkaoui, and M. Paolone, "Security constrained unit commitment with dynamic thermal line rating," IEEE. Trans. Power Syst., vol. 31, pp. 2014-2025, May 2016.

[15] B. Xu, A. Ulbig, and G. Andersson, "Impacts of dynamic line rating on power dispatch performance and grid integration of renewable energy sources," In proc. 4th IEEE/PES. Innovative Smart Grid Tech. Europe conf., pp. 1-5, Oct. 2013.

[16] M. Wang and X. Han, "Study on electro-thermal coupling optimal power flow model and its simplification," In IEEE. PES. General Meeting, pp. 16, July 2010.

[17] S. Kumari, G. Priyanka and M. Sydulu, "Comparison of Genetic Algorithms and Particle Swarm Optimization for Optimal Power Flow Including FACTS devices," in proc.2007 IEEE. Lausanne Power Tech., Lausanne, Switzerland, pp. 1105 - 1110, 1-5 July 2007.

[18] K. Pandya, and S. Joshi, "A Survey of the Optimal Power Flow Methods", J. Theoretical. Appl. Inf. Tech., pp. 450-458, 2008.

[19] Z. Lubosny, "Wind Turbine Operation in Electric Power Systems," Berlin: Springer, pp. 19-20, 2003.

[20] W. Zhou, Y. Peng, and H. Sun, "Optimal wind-thermal coordination dispatch based on risk reserve constraints," European Trans. Elect. Power, vol. 21, no. 1, pp. 740-756, Jan. 2011.

[21] R. Jabr, and B. Pal, "Intermittent wind generation in optimal power flow dispatching," IET. Gen. Trans. Dist., vol. 3, no. 1, pp. 66-74, Jan. 2009.

[22] H. Siahkali, and M. Vakilian, "Electricity generation scheduling with largescale wind farms using particle swarm optimization," Elect. Power. Syst. Res., vol. 79, no. 5, pp. 826-836, May 2009.

[23] Y. Sun, J. Wu, G. Li and J. He, "Dynamic economic dispatch considering wind power penetration based on wind speed forecasting and stochastic programming,".in Proc. CSEE, vol. 29, pp. 41-47, Mar. 2009.

[24] L. Wang and C. Singh, "Balancing risk and cost in fuzzy economic dispatch including wind power penetration based on particle swarm optimization," Elect. Power. Syst. Res., vol. 78, no. 8, pp. 1361-1368, Aug. 2008.

[25] J. Hetzer, D. Yu, and K. Bhattarai, "An economic dispatch model incorporating wind power," IEEE. Trans. Energy Conv., vol. 23, no. 2, pp. 603-611, Jun. 2008.

[26] N.E. Jose and K. Ramesh "Survey on Optimal Power Flow under Security Constraints”, Int. J. Emerging Tech. Advanced Eng. Vol. 3, no. 1, Jan. 2013.

[27] W. Rebizant, and L. Staszewski, "The differences between IEEE and CIGRE heat balance concepts for line ampacity considerations," in proc., 2010 Modern. Elect. Power Syst., Wroclaw, Poland, pp. 1-4 20-22, Sept. 2010.

[28] J. Fu, S. Abbott, B. Fox, D. Morrow, and S. Abdelkader, "Wind cooling effect on dynamic overhead line ratings," In proc. 45th Univ. Power. Eng. Conf., Oct. 2010.

[29] IEEE PES., "IEEE Standard for calculating the current-temperature relationship of bare overhead conductors," IEEE. Std.738-2012Cor.1-2013, pp. 1-72, Dec. 2013.

[30] A.A.EL-Desouky, "Security constrained generation scheduling for grids incorporating wind, photovoltaic and thermal power", Elect. Power Syst. Res., vol. 116, pp. 284-292, Sept. 2014.

[31] T. Niknam, and M. Abarghooee, "A new hybrid algorithm for optimal power flow considering prohibited zones and valve point effect," Energy. Conv. Management, vol. 58, pp. 197-206, June 2012. 
[32] A. Mohamed, Y. Mohamed and A. El-Gaafary, "Optimal power flow using moth swarm algorithm," Elect. Power. Syst. Res., vol. 142, pp. 190-206, Jan. 2017.

[33] A. Chaib, H. Bouchekara, R. Mehasni, and M. Abido. "Optimal power flow with emission and non- smooth cost functions using backtracking search optimization algorithm," Int. J. Elect. Power Energy Syst., vol. 81, pp. 6477, Oct. 2016.

[34] H. Bouchekara, A. Chaib, M. Abido, and R. El-Sehiemy "Optimal power flow using an Improved Colliding Bodies Optimization algorithm," Appl. Soft. Comput. vol. 42, pp. 119-131, May 2016.

[35] A. Panda, and M. Tripathy. "Security constrained optimal power flow solution of wind-thermal generation system using modified bacteria foraging algorithm," Energy, vol. 93, no. 1, pp. 816-827, Dec. 2015.

[36] C. N.Ravi, C. christober, "Emission Constraints Optimal Power Flow Using Differential Evolution”. Int. J. comput. App, Jan 2013.

[37] A. Eladl, and A. ElDesouky, "Optimal economic dispatch for multi heatelectric energy source power system," Int. J. Elect. Power Energy Syst., vol. 110, pp. 21-35, Sept. 2019.

[38] O. Alsac, and B. Stott. "Optimal load flow with steady-state security." IEEE trans power app. syst.," vol. 3, no. 3, pp. 745-751, Apr. 1974.

[39] Midal Cables, IOverhead Conductor Data Sheets, Available, from: https: // www. midalcable.com, 2016.

[40] A. Elmitwally, A. Eladl and J. Morrow, "A Long -Term Economic Model for Allocation of FACTS Devices in Restructured Power Systems Integrating Wind Generation," IET. Gen. Trans. Dist., vol. 10, no. 1, pp. 19-30, Jan. 2016.

[41] B. O. Ngoko, H. Sugihara and T. Funaki, "Effect of Dynamic Line ratings on Optimal Dispatch Considering Uncertainty Costs due to Intermittent Renewable Energy," IFAC conference paper archive, pp. 185-190, Jan. 2018.

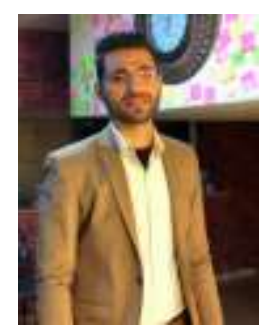

Ahmed A. Elsherpiny was born in MetAnter village, Talkha city, in 1989. He received a bachelor's degree in electrical engineering from Mansoura University, Egypt, in 2011. He worked in the field of engineering training. He was a research assistant at the Faculty of Engineering, Mansoura University, Department of Mathematics and Engineering Physics. He is currently a demonstrator of the higher Nile institute of engineering, Department of communication and electronics. Mansoura, Egypt. His areas of interest are diverse which cover power system operation and control, green energy sources into electrical grids, and energy storage.

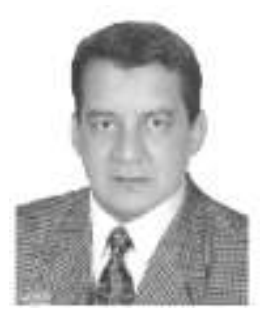

Sobhy M. Abdelkader, was born in Salahat, Egypt in 1961. He obtained the B. Sc., M.Sc. and Ph.D. degrees all in Electrical Engineering from Mansoura University, Egypt in 1984, 1989 and 1995 respectively. Since 1984, he has been employed by the Electrical Engineering Department at Mansoura University, where he is now a professor . He joined Queen's University Belfast as a Senior Research Fellow in Nov. 2007 until Dec 2014. He joined Egypt -Japan University E-JUST in August 2019, as the Head of the Electrical Power Engineering Department. His research interests include power system analysis and control, wind power integration into electrical grids, and electrical energy markets.

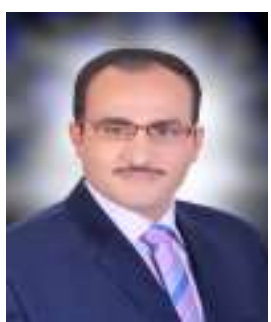

Abdelfattah A. Eladl, He obtained B.Sc. (Ranked first, with honor), M.Sc. and Ph.D. all are in Electrical Engineering from Mansoura University, EL-Mansoura, Egypt. Currently, he is an assistant professor at the electrical engineering department, Mansoura University, Egypt. In 2016 he receives the best Ph.D. thesis award from Mansoura University. His fields of interest include power system economics, planning, power quality, and energy hubs.

\section{Title Arabic: \\ دمج سعة الخط الديناميكية فى السريان الامثل للطاقة المقيا

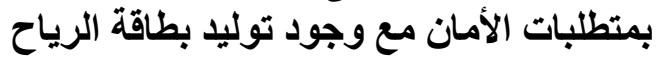

\section{Arabic Abstract:}

يتم حل مشكلة تدفق الطاقة المثلى (OPF) التقليدية باعتبار ان الظروف الجوية

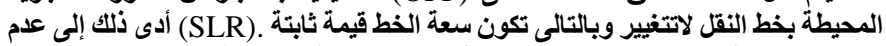

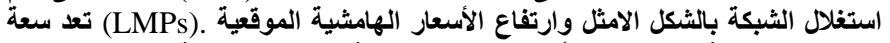

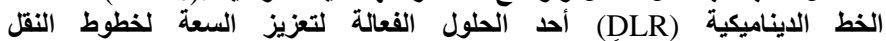

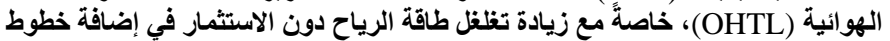

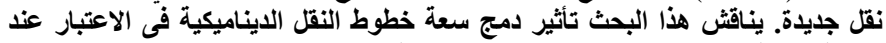

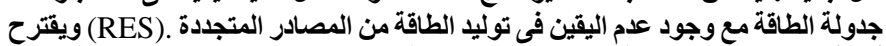

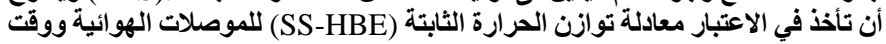

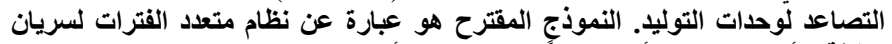

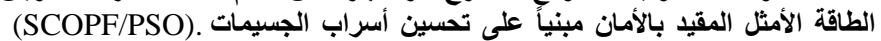

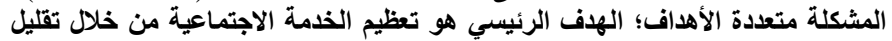

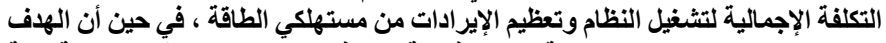

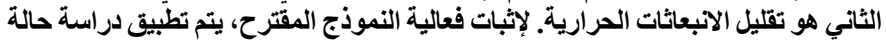

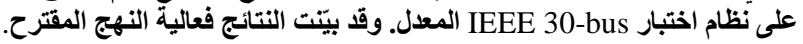

